Arq. Bras. Med. Vet. Zootec., v.56, n.3, p.355-362, 2004

\title{
Efeito da suplementação e do intervalo de pastejo sobre a qualidade da forragem e consumo voluntário de vacas Holandês $\times$ Zebu em lactação em pastagem de capim-elefante
}

\author{
[Effect of supplementation and resting period on forage quality and voluntary intake of elephantgrass grazed by \\ lactating Holstein $\times$ Zebu cows] \\ F.C.F. Lopes ${ }^{1}$, L.J.M. Aroeira ${ }^{1}$, N.M. Rodriguez ${ }^{2}$, F. Deresz ${ }^{1}$, \\ I.B.M. Sampaio ${ }^{2}$, D.S.C. Paciullo ${ }^{3}$, A. Vittori ${ }^{4}$ \\ ${ }^{1}$ Embrapa Gado de Leite \\ Rua Eugênio do Nascimento, 610, Bairro Dom Bosco \\ 36038-330 - Juiz de Fora, MG \\ ${ }^{2}$ Escola de Veterinária da UFMG - Belo Horizonte, MG \\ ${ }^{3}$ Embrapa Gado de Leite (Bolsista recém-doutor - CNPq) \\ ${ }^{4}$ Doutoranda no Depto. de Zootecnia - UFV - Viçosa, MG
}

\section{RESUMO}

O trabalho foi realizado entre fevereiro e setembro, com o objetivo de avaliar a qualidade e o consumo de forragem de capim-elefante manejado sob pastejo rotativo, com período de ocupação dos piquetes de três dias e variação do intervalo de pastejo de: 30 dias (com e sem o uso de concentrado ao longo do ano) e 36 e 45 dias (sem o uso de concentrado). Foram usadas 24 vacas Holandês $\times$ Zebu em lactação. De fevereiro a maio o pasto foi o único volumoso. De junho a setembro, as vacas receberam cana mais $1 \%$ de uréia. A composição química de extrusas de capim-elefante foi, de modo geral, semelhante $(\mathrm{P}>0,05)$ entre intervalos de pastejo (6,1 a 18,2\% para PB; 63,5 a 81,4\% para FDN; 32,7 a 47,6\% para FDA e 43,7 a $72,9 \%$ para digestibilidade in vitro da MS). Houve decréscimo no teor de PB do capim-elefante e aumento nos de FDN e FDA para cada dia adicional de ocupação do piquete $(\mathrm{P}<0,0001)$. Na estação chuvosa, o consumo diário de capim-elefante foi, de modo geral, semelhante $(\mathrm{P}>0,05)$ nos diferentes intervalos de pastejo, variando de 1,7 a 3,6\%PV para MS e de 1,1 a 2,7\%PV para FDN. Na estação seca, nas pastagens sem concentrado, o consumo de MS do capim-elefante variou de 0,39 a $2,2 \% \mathrm{PV}$ e sua contribuição no consumo total da dieta decresceu de $52 \%$ no primeiro para $43 \%$ no terceiro dia de ocupação do piquete. $\mathrm{O}$ consumo suplementar de cana mais uréia foi efetivo em minimizar a redução no consumo total de MS.

Palavras-chave: cana-de-açúcar, digestibilidade in vitro, indicador, intervalo de pastejo, óxido crômico

\begin{abstract}
Mean daily dry matter intake of elephantgrass (DMI) (Pennisetum purpureum, Schumack) in a rotational grazing with lactating Holstein $\times$ Zebu cows was estimated in a trial carried out from February to September. The pasture was divided into paddocks and grazed for three days by 24 cows randomly allotted to four treatments. The treatments consisted on grazing intervals of 30 days, and concentrate (2kg/cow/day) and grazing intervals of 30, 36 or 45 days without concentrate. From February to May the elephantgrass was the only roughage, but from June to September (dry season) the cows were fed on chopped sugarcane plus 1\% urea. DMI was estimated monthly using the extrusa in vitro dry matter digestibility (IVDMD) and the fecal output (chromium oxide). The average chemical composition of
\end{abstract}

Recebido para publicação em 23 de maio de 2003

Recebido para publicação, após modificações, em 29 de outubro de 2003

E-mail: fernando@cnpgl.embrapa.br 
extrusa was generally similar ( $P>.05)$ among grazing intervals (6.1 to $18.2 \%$ of $C P ; 63.5$ to $81.4 \%$ of $N D F ; 32.7$ to $47.6 \%$ of $A D F$ and 43.7 to $72.9 \%$ of IVDMD). The CP content of extrusas decreased and the NDF and $A D F$ contents increased $(P<.0001)$ with the paddock occupation day. In the rainy season the DMI (1.68 to $3.57 \% \mathrm{BW})$ and daily NDF intake (1.14 to $2.67 \% \mathrm{BW})$ were generally similar $(P>.05)$ among grazing intervals. During the dry season cows fed on treatments without concentrate the DMI varied from .39 to $2.2 \% \mathrm{BW}$ and its contribution to total DM intake decresead from $52 \%$ in the first to $43 \%$ in the third day of paddock occupation. Sugarcane intake effectively minimized the effects of the low pasture intake in the dry season.

Keywords: sugarcane, in vitro digestibility, marker, grazing interval, chromium oxide

\section{INTRODUÇÃO}

Com cerca de $80 \%$ de seu território concentrado na faixa tropical, o Brasil apresenta inquestionável aptidão para produção de leite em sistemas baseados em pastagens. As gramíneas prevalecentes no país são do tipo $\mathrm{C}_{4}$, com características de alta eficiência fotossintética e elevada taxa de crescimento (Assis, 1997).

Dentre várias forrageiras, o capim-elefante (Pennisetum purpureum, Schumack) tem merecido especial atenção, sendo recomendado para sistemas intensivos de produção de leite a pasto (Deresz, 1999; Cóser et al., 2000). Entretanto, mesmo apresentando forragem com alta qualidade nutritiva, a estacionalidade de sua produção indica a necessidade de suplementação da pastagem na estação seca do ano (Aroeira et al., 1999; Soares et al., 1999).

Em face da alta produtividade alcançada com a cultura (Torres, 1999) e o elevado teor de carboidratos não-estruturais observados na estação seca do ano (Rodrigues, 1999), a canade-açúcar (corrigida com 1\% de uréia:sulfato de amônio na proporção 9:1) é um dos principais suplementos volumosos recomendados, para minimizar os efeitos sazonais da produção de forragem do capim-elefante (Martins et al., 1998).

Existem poucos trabalhos de avaliação sistemática do consumo de nutrientes e da qualidade nutricional do capim-elefante selecionado por vacas em lactação ao longo do ano, o que demonstra a necessidade de estudos adicionais sobre o tema.

Foi objetivo deste estudo avaliar a composição química e o consumo de vacas Holandês $\times$ Zebu em lactação em pastagens de capim-elefante suplementadas ou não com concentrado ao longo do ano e com cana mais uréia na estação seca em sistemas manejados com diferentes intervalos de pastejo.

\section{MATERIAL E MÉTODOS}

O experimento foi conduzido de fevereiro a setembro de 1994 na Embrapa Gado de Leite (Coronel Pacheco, MG). A pastagem de capimelefante foi dividida em piquetes e manejada em sistema rotativo. Os tratamentos avaliados foram intervalos de pastejo de 30 dias com e de 30 dias sem concentrado, e de 36 e 45 dias sem concentrado. O concentrado $(81,1 \%$ de $\mathrm{MS}$; $19,6 \%$ de $\mathrm{PB}$ e $22,8 \%$ de FDN) foi fornecido individualmente $(2 \mathrm{~kg} / \mathrm{vaca} / \mathrm{dia})$ durante as ordenhas. Para assegurar taxa de lotação uniforme entre tratamentos (4,5 vacas/ha), os piquetes variaram em número e tamanho $(11,13$ ou 16 piquetes, medindo 607,513 ou $417 \mathrm{~m}^{2}$, respectivamente para intervalos de pastejo de 30 , 36 e 45 dias). O período de ocupação dos piquetes foi de três dias, com duas repetições de área de pastagem por tratamento.

No experimento foram usadas 24 vacas mestiças Holandês $\times$ Zebu, distribuídas em delineamento de blocos ao acaso em função da produção de leite e do peso vivo, registrados no período préexperimental, o que correspondeu a 6 vacas/tratamento. Elas foram pesadas quinzenalmente e ordenhadas duas vezes ao dia.

De fevereiro a maio, o único volumoso disponível foi o pasto de capim-elefante. $\mathrm{Na}$ estação seca (junho a setembro), a entrada das vacas nos piquetes ocorreu após a ordenha da tarde, onde permaneceram até a ordenha da manhã seguinte. No intervalo entre ordenhas 
receberam, no curral, cana-de-açúcar (Saccharum officinarum, L.) picada e corrigida com $1 \%$ da mistura uréia:sulfato de amônia na proporção 9:1 (base matéria natural).

O consumo individual diário de matéria seca (MS) das 24 vacas foi estimado pela fórmula: consumo $(\mathrm{kg}$ de $\mathrm{MS})=$ produção fecal $\times$ $100 /(100$ - digestibilidade) em oito ocasiões consecutivas nas estações da chuva (fevereiro, março, abril e maio) e da seca (junho, julho, agosto e setembro). A produção fecal total foi obtida com óxido crômico administrado $(10 \mathrm{~g} / \mathrm{vaca} / \mathrm{dia})$ via oral às vacas durante 12 dias. Nos últimos seis dias foram colhidas fezes, cujos teores de cromo foram analisados por espectrofotometria de absorção atômica, após digestão nitroperclórica (Kimura e Miller, 1957).

Os consumos foram estimados a partir de valores de digestibilidade in vitro da MS (DIVMS; Tilley e Terry, 1963) de extrusas de dois bovinos adultos fistulados no esôfago, obtidas no primeiro, segundo e terceiro dias de ocupação do piquete. A produção fecal foi calculada das concentrações de cromo nas fezes colhidas 48 horas após a coleta da extrusa.

Com o término das coletas diárias, as extrusas foram armazenadas a $-10^{\circ} \mathrm{C}$ e, posteriormente, descongeladas, homogeneizadas, pré-secas em estufa de ventilação forçada $\left(65^{\circ} \mathrm{C}, 72 \mathrm{~h}\right)$, moídas em moinho de facas (peneira com perfurações de $1 \mathrm{~mm}$ ) e analisadas (Silva, 1998) para teores de MS, de proteína bruta (PB), de fibras em detergente neutro (FDN) e detergente ácido (FDA) e de DIVMS.

Foram feitas amostragens diárias do concentrado, sendo transformadas em compostas/mês. O consumo de cana mais uréia foi obtido do registro diário do oferecido e das sobras. Todas essas amostras foram analisadas conforme relatado para extrusa.

Os dados de consumo diário de MS e de FDN (expressos como porcentagem do peso vivo/dia, \%PV) e de composição química das extrusas (PB, FDN, FDA e DIVMS) foram analisados em parcelas subsubdivididas, com os tratamentos nas parcelas e os dias de ocupação do piquete nas subsubparcelas, usando o procedimento GLM e as regressões obtidas com o procedimento REG (User's..., 1985).

\section{RESULTADOS E DISCUSSÃO}

Houve interações $(\mathrm{P}<0,05)$ entre os efeitos testados (mês, tratamento e dias de ocupação do piquete) nas variáveis de composição química das extrusas.

As concentrações de PB, FDN, FDA e DIVMS da extrusa em cada dia de ocupação do piquete nos intervalos de pastejo de 30 dias foram semelhantes $(\mathrm{P}>0,05)$, mostrando que, de modo geral, não houve efeito da suplementação concentrada sobre essas variáveis.

Nos tratamentos sem concentrado, em cada dia de ocupação do piquete, foi observada semelhança $(\mathrm{P}>0,05)$ na DIVMS e nos teores de FDN e FDA das extrusas nos intervalos de pastejo de 30, 36 e 45 dias.

$\mathrm{Na}$ estação das chuvas, no primeiro dia de ocupação do piquete, a regressão do teor médio de PB (Y) em relação ao intervalo de pastejo (X) não foi significativa $(\mathrm{P}>0,05)$, indicando semelhança entre tratamentos para essa variável. No segundo e terceiro dias de ocupação do piquete foram observados decréscimos $(\mathrm{P}<0,0233)$ de 0,19 e $0,16 \%$ na $\mathrm{PB}$ da extrusa, respectivamente, para cada dia adicional no intervalo de pastejo. $\mathrm{Na}$ estação da seca, no segundo dia de ocupação do piquete, houve incremento $(\mathrm{P}<0,0377)$ de $0,12 \%$ de $\mathrm{PB}$ da extrusa para cada dia adicional no intervalo de pastejo.

Independentemente do tratamento, houve superioridade $(\mathrm{P}<0,05)$ dos teores de $\mathrm{PB}$ do primeiro em relação ao terceiro dia de ocupação do piquete. Resultados semelhantes foram relatados por Cóser et al. (2000) e Aroeira et al. (2001). A diferença foi mais evidente a partir de maio, quando também a PB da extrusa do segundo dia foram inferiores $(\mathrm{P}<0,05)$ às do primeiro dia de ocupação do piquete.

De fevereiro a setembro houve decréscimo $(\mathrm{P}<0,0001)$ de $2,1 \%$ na $\mathrm{PB}$ da extrusa para cada dia adicional de ocupação do piquete. Nos meses da estação chuvosa, as diferenças foram 
menores, com decréscimos $(\mathrm{P}<0,0008)$ de $1,5 \%$ de $\mathrm{PB}$ para cada dia adicional de ocupação do piquete. Nos meses da seca, houve redução $(\mathrm{P}<0,0001)$ de $2,8 \%$ de $\mathrm{PB}$ das extrusas para cada dia adicional de ocupação do piquete.

Nos meses da estação chuvosa, as respectivas concentrações de FDA nos primeiros e segundos dias de ocupação do piquete foram, de modo geral, semelhantes $(\mathrm{P}>0,05)$ e menores $(\mathrm{P}<0,05)$ que as observadas nos terceiros dias de ocupação dos piquetes. A partir de maio, com a entrada da estação seca do ano, foi verificada maior discriminação nos teores de FDA, que diminuíram $(\mathrm{P}<0,05)$ do primeiro em relação aos demais dias de ocupação do piquete. A regressão do teor de FDA (Y) em relação ao dia de ocupação do piquete $(\mathrm{X})$ no período de fevereiro a setembro indicou aumento na extrusa $(\mathrm{P}<0,0001)$ de $2,7 \%$ de FDA para cada dia adicional de ocupação do piquete. Nos meses da estação das chuvas, o incremento foi menor $(\mathrm{P}<0,0001)$ que o observado na estação seca do ano ( 2,4 versus $2,9 \%$ de FDA).

De fevereiro a setembro houve incremento $(\mathrm{P}<0,0001)$ na extrusa de $1,8 \%$ de FDN por dia adicional de ocupação do piquete. Nos meses da estação chuvosa, isto foi mais evidente, com acréscimo $(\mathrm{P}<0,0001)$ de $2,0 \%$ no teor de FDN da extrusa por dia adicional de ocupação do piquete.

$\mathrm{Na}$ literatura brasileira, sob ciclos de pastejo de 32 a 48 dias, a composição química do pasto de capim-elefante na estação das chuvas (amostras de extrusa ou simulação de pastejo) variou de 7,1 a $16,2 \%$ para $\mathrm{PB} ; 62,6$ a $75,2 \%$ para FDN; 35,6 a $44,1 \%$ para FDA; e 50,0 a $68,5 \%$ para DIVMS (Deresz, 1994; Balsalobre et al., 1996; Lopes et al., 1998; Aroeira et al., 1999; Soares et al., 1999; Erbesdobler et al., 2000; Paciullo et al., 2001). Na estação seca, os teores médios relatados variaram de 9,2 a 19,1\% (PB); 64,1 a $73,8 \%$ (FDN); 34,0 a $41,2 \%$ (FDA); e 50,7 a 67,6\% (DIVMS) (Rocha, 1987; Aroeira et al., 1999; Lopes e Aroeira, 1999; Soares et al., 1999). No presente estudo, na estação chuvosa, os teores na extrusa situaram-se entre 6,1 e $17,5 \%$ (PB); 65,6 e 79,3\% (FDN); 34,2 e 47,6\% (FDA); e 43,7 e 69,3\% (DIVMS). Na estação seca, foram observados valores entre 7,9 e $18,2 \%$ (PB); 63,5 e 81,4\% (FDN); 32,7 e 45,1\% (FDA); e 47,4 e $72,9 \%$ (DIVMS). A maior amplitude de variação na composição química do capimelefante deste estudo pode ser parcialmente atribuída à combinação dos fatores dias de ocupação do piquete, tratamentos e meses do ano.

Verificou-se interação $(\mathrm{P}<0,05)$ mês $\times$ tratamento $\times$ dia de ocupação do piquete para consumo diário de MS e de FDN (pastagem ou total). Na Tab. 1 é apresentado o consumo médio diário de MS de capim-elefante (\%PV) estimado nos meses da estação chuvosa (fevereiro a maio) em função dos tratamentos e dias de ocupação do piquete.

Tabela 1. Consumo médio diário de MS de pastagem de capim-elefante (\%PV) nos meses da estação das chuvas, em função do intervalo de pastejo, da suplementação concentrada e dos dias de ocupação do piquete

\begin{tabular}{|c|c|c|c|c|c|c|c|c|c|c|c|c|}
\hline \multirow{3}{*}{ Mês } & \multirow{2}{*}{\multicolumn{3}{|c|}{$\begin{array}{c}30 \text { dias com concentrado } \\
\text { Dias de ocupação }\end{array}$}} & \multirow{2}{*}{\multicolumn{3}{|c|}{$\begin{array}{c}30 \text { dias sem concentrado } \\
\text { Dias de ocupação }\end{array}$}} & \multirow{2}{*}{\multicolumn{3}{|c|}{$\begin{array}{c}36 \text { dias sem concentrado } \\
\text { Dias de ocupação }\end{array}$}} & \multirow{2}{*}{\multicolumn{3}{|c|}{$\begin{array}{c}45 \text { dias sem concentrado } \\
\text { Dias de ocupação }\end{array}$}} \\
\hline & & & & & & & & & & & & \\
\hline & 1 & 2 & 3 & 1 & 2 & 3 & 1 & 2 & 3 & 1 & 2 & 3 \\
\hline Fevereiro & $3,53 \mathrm{aA}$ & $3,08 \mathrm{bA}$ & $2,90 \mathrm{bB}$ & $3,02 \mathrm{aB}$ & $3,12 \mathrm{aA}$ & $2,93 \mathrm{aB}$ & $3,03 \mathrm{bB}$ & $2,91 \mathrm{bA}$ & $3,50 \mathrm{aA}$ & $2,23 \mathrm{bC}$ & $2,94 \mathrm{aA}$ & $2,58 \mathrm{abB}$ \\
\hline Março & $3,57 \mathrm{aA}$ & $3,23 \mathrm{aAB}$ & $3,26 \mathrm{aA}$ & $3,16 \mathrm{aAB}$ & $2,81 \mathrm{aBC}$ & $2,99 \mathrm{aAB}$ & $3,17 \mathrm{aAB}$ & $2,76 \mathrm{bC}$ & $2,68 \mathrm{bB}$ & $2,85 \mathrm{bB}$ & $3,40 \mathrm{aA}$ & $2,82 \mathrm{bAB}$ \\
\hline Abril & $3,08 \mathrm{aA}$ & $2,89 \mathrm{aA}$ & $2,90 \mathrm{aA}$ & $2,97 \mathrm{aA}$ & $2,53 \mathrm{bA}$ & 2,79abA & $3,04 \mathrm{aA}$ & $2,90 \mathrm{aA}$ & $3,12 \mathrm{aA}$ & $3,21 \mathrm{aA}$ & $2,71 \mathrm{bA}$ & $2,85 \mathrm{abA}$ \\
\hline Maio & $1,96 \mathrm{bBC}$ & $2,36 \mathrm{aB}$ & $1,87 \mathrm{bB}$ & $2,27 \mathrm{aB}$ & $1,82 \mathrm{bC}$ & $2,18 \mathrm{abB}$ & $1,68 \mathrm{cC}$ & $2,38 \mathrm{bB}$ & $3,03 \mathrm{aA}$ & $3,17 \mathrm{aA}$ & $2,94 \mathrm{aA}$ & $3,03 \mathrm{aA}$ \\
\hline
\end{tabular}

Coefíciente de variação da análise de variância $=11,8 \%$.

Em um mesmo tratamento, letras minúsculas distintas indicam médias diferentes $(P<0,05)$ entre dias de ocupação do piquete $($ dms $=$ $0,38 \% \mathrm{PV})$

Em um mesmo dia de ocupação do piquete, letras maiúsculas distintas indicam médias diferentes $(\mathrm{P}<0,05)$ entre tratamentos $(\mathrm{dms}=$ $0,45 \% \mathrm{PV})$.

Nas pastagens com 30 dias de intervalo de pastejo houve efeito $(\mathrm{P}<0,05)$ do concentrado sobre o consumo diário de $\mathrm{MS}$ de pasto $(\% \mathrm{PV})$ em apenas dois dias de ocupação do piquete nos meses da estação chuvosa. Nesse período, o consumo adicional de MS de concentrado 
$(0,30 \% \mathrm{PV})$ permitiu incremento $(\mathrm{P}<0,05)$ no consumo diário total de $\mathrm{MS}(\% \mathrm{PV})$ na pastagem suplementada.

De fevereiro a abril, nos tratamentos sem concentrado, apenas em dias esporádicos de ocupação do piquete houve efeito $(\mathrm{P}<0,05)$ do intervalo de pastejo sobre o consumo diário de MS de capim-elefante. Porém, em maio, na pastagem com 45 dias de intervalo de pastejo a ingestão diária de MS (\%PV) foi superior $(\mathrm{P}<0,05)$. Nesse mês, de forma distinta ao observado nos demais tratamentos, houve incremento nos valores de DIVMS da extrusa da pastagem com 45 dias de intervalo de pastejo. Conquanto não tenham sido encontradas justificativas para o comportamento observado para os valores de DIVMS, pôde-se perceber sua influência nas estimativas de consumo, obtidas pela técnica do óxido crômico/indigestibilidade da dieta, sugerindo que técnicas de estimativas de consumo individual de pastagem, com menor relação de dependência da análise de DIVMS, devam ser pesquisadas (e.g. técnica dos $n$ alcanos).

De fevereiro a abril, principalmente nas pastagens com 30 dias de intervalo de pastejo, o consumo de capim-elefante (\%PV) estimado para os três dias de ocupação do piquete foi, de modo geral, semelhante $(\mathrm{P}>0,05)$, mas nos tratamentos com 36 e 45 dias de intervalo de pastejo, houve meses em que o segundo ou terceiro dias de ocupação do piquete apresentaram maior consumo $(\mathrm{P}<0,05)$ do que o primeiro (Tab. 1).

Nos tratamentos sem concentrado, nos meses da estação chuvosa, o consumo de FDN (\%PV), estimado nos três dias de ocupação do piquete, foi alto em relação ao valor de $1,2 \pm 0,1 \% \mathrm{PV}$ apresentado por Mertens (1992) para vacas em lactação. De fevereiro a maio, o consumo médio diário de FDN proveniente das dietas exclusivas de capim-elefante variou de 1,1 a $2,7 \% \mathrm{PV}$. Na pastagem suplementada, o consumo diário de FDN do concentrado foi de $0,07 \% \mathrm{PV}$ e o consumo diário total de FDN (pastagem + concentrado) variou de 1,4 a 2,6\%PV.

$\mathrm{Na}$ estação das chuvas, para vacas Holandês $\times$ Zebu em lactação, Benedetti (1994) relatou consumo de MS de pastagens de capim-elefante, de braquiária (Brachiaria decumbens) e de colonião (Panicum maximum), respectivamente de 2,$7 ; 2,8$ e $3,0 \% \mathrm{PV}$, sendo o consumo de FDN (calculado por inferências matemáticas com os dados médios disponibilizados pelo autor) de 2,$1 ; 2,2$ e $2,3 \% \mathrm{PV}$, respectivamente. A suplementação concentrada das pastagens ( $4 \mathrm{~kg} / \mathrm{vaca} /$ dia) elevou o consumo total de MS das vacas para 3,$4 ; 3,5$ e $3,6 \% \mathrm{PV}$ e o de FDN para 2,$8 ; 2,9$ e $3,0 \% \mathrm{PV}$, respectivamente, para o capim-elefante, braquiária e colonião. Para intervalos de pastejo de capim-elefante de 30 a 45 dias, Aroeira et al. (1999) relataram, na estação das chuvas, consumo de MS e de FDN variando, respectivamente, de 3,1 a $3,7 \% \mathrm{PV}$ e de 2,3 a $2,8 \%$ PV para vacas Holandês $\times$ Zebu em lactação. No presente trabalho, pode-se perceber a elevada capacidade de vacas Holandês $\times$ Zebu na ingestão de FDN de pastagens com forrageiras tropicais.

Nas Tab. 2 e 3 têm-se, respectivamente, o consumo médio diário $(\% \mathrm{PV})$ de $\mathrm{MS}$ de pastagem e o consumo total (pasto mais suplementos) estimados na estação seca (junho a setembro), em função dos tratamentos e dias de ocupação do piquete.

Tabela 2. Consumo médio diário de MS de pastagem de capim-elefante (\%PV) nos meses da estação da seca, em função do intervalo de pastejo, da suplementação concentrada e dos dias de ocupação do piquete

\begin{tabular}{|c|c|c|c|c|c|c|c|c|c|c|c|c|}
\hline \multirow{3}{*}{ Mês } & \multirow{2}{*}{\multicolumn{3}{|c|}{$\begin{array}{c}30 \text { dias com concentrado } \\
\text { Dias de ocupação }\end{array}$}} & \multirow{2}{*}{\multicolumn{3}{|c|}{$\begin{array}{c}30 \text { dias sem concentrado } \\
\text { Dias de ocupação }\end{array}$}} & \multirow{2}{*}{\multicolumn{3}{|c|}{$\begin{array}{c}36 \text { dias sem concentrado } \\
\text { Dias de ocupação }\end{array}$}} & \multirow{2}{*}{\multicolumn{3}{|c|}{$\begin{array}{c}45 \text { dias sem concentrado } \\
\text { Dias de ocupação }\end{array}$}} \\
\hline & & & & & & & & & & & & \\
\hline & 1 & 2 & 3 & 1 & 2 & 3 & 1 & 2 & 3 & 1 & 2 & 3 \\
\hline Junho & $2,11 \mathrm{aA}$ & $2,07 \mathrm{aA}$ & $1,85 \mathrm{aA}$ & $2,05 \mathrm{aA}$ & $1,66 \mathrm{bBC}$ & $1,73 \mathrm{bA}$ & $1,93 \mathrm{aA}$ & $1,32 \mathrm{bC}$ & $1,40 \mathrm{bB}$ & $1,42 \mathrm{bB}$ & $1,77 \mathrm{aAB}$ & $1,59 \mathrm{abAB}$ \\
\hline Julho & $1,30 \mathrm{aB}$ & $1,24 \mathrm{aA}$ & $1,38 \mathrm{aA}$ & $1,65 \mathrm{aB}$ & $1,26 \mathrm{bA}$ & $0,88 \mathrm{cB}$ & $2,23 \mathrm{aA}$ & $1,52 \mathrm{bA}$ & $1,50 \mathrm{bA}$ & $1,36 \mathrm{aB}$ & $1,25 \mathrm{aA}$ & $1,10 \mathrm{aAB}$ \\
\hline Agosto & $1,35 \mathrm{aB}$ & $0,95 \mathrm{bAB}$ & $1,13 \mathrm{abAB}$ & $2,01 \mathrm{aA}$ & $1,31 \mathrm{bA}$ & $1,16 \mathrm{bA}$ & $0,58 \mathrm{aC}$ & $0,49 \mathrm{aC}$ & $0,66 \mathrm{aC}$ & $0,39 \mathrm{bC}$ & $0,70 \mathrm{aB}$ & $0,74 \mathrm{aBC}$ \\
\hline Setembro & $0,39 \mathrm{aC}$ & $0,40 \mathrm{aC}$ & $0,30 \mathrm{aB}$ & $1,17 \mathrm{aA}$ & $1,00 \mathrm{aA}$ & $1,04 \mathrm{aA}$ & $0,74 \mathrm{aBC}$ & $0,58 \mathrm{aBC}$ & $0,51 \mathrm{aB}$ & $1,07 \mathrm{aAB}$ & $0,87 \mathrm{abAB}$ & $0,61 \mathrm{bB}$ \\
\hline
\end{tabular}

Coeficiente de variação da análise de variância $=19,5 \%$.

Em um mesmo tratamento, letras minúsculas distintas indicam médias diferentes $(\mathrm{P}<0,05)$ entre dias de ocupação do piquete $(\mathrm{dms}=$ $0,26 \% \mathrm{PV})$

Em um mesmo dia de ocupação do piquete, letras maiúsculas distintas indicam médias diferentes $(\mathrm{P}<0,05)$ entre tratamentos $(\mathrm{dms}=$ $0,40 \% \mathrm{PV})$. 
Tabela 3. Consumo médio diário total de MS (\%PV) nos meses da estação da seca, em função do intervalo de pastejo, da suplementação concentrada e dos dias de ocupação do piquete

\begin{tabular}{|c|c|c|c|c|c|c|c|c|c|c|c|c|}
\hline \multirow{3}{*}{ Mês } & \multirow{2}{*}{\multicolumn{3}{|c|}{$\begin{array}{c}30 \text { dias com concentrado } \\
\text { Dias de ocupação }\end{array}$}} & \multirow{2}{*}{\multicolumn{3}{|c|}{$\begin{array}{c}30 \text { dias sem concentrado } \\
\text { Dias de ocupação }\end{array}$}} & \multirow{2}{*}{\multicolumn{3}{|c|}{$\begin{array}{c}36 \text { dias sem concentrado } \\
\text { Dias de ocupação }\end{array}$}} & \multirow{2}{*}{\multicolumn{3}{|c|}{$\begin{array}{c}45 \text { dias sem concentrado } \\
\text { Dias de ocupação }\end{array}$}} \\
\hline & & & & & & & & & & & & \\
\hline & 1 & 2 & 3 & 1 & 2 & 3 & 1 & 2 & 3 & 1 & 2 & 3 \\
\hline Junho & $3,33 \mathrm{aA}$ & $3,22 \mathrm{aA}$ & $3,18 \mathrm{aA}$ & $3,08 \mathrm{aA}$ & $2,62 \mathrm{bBC}$ & $2,83 \mathrm{abAB}$ & $3,03 \mathrm{aA}$ & $2,37 \mathrm{bC}$ & $2,61 \mathrm{bH}$ & $2,45 \mathrm{bB}$ & $2,81 \mathrm{aAB}$ & $2,74 \mathrm{abB}$ \\
\hline Julho & & $2,55 \mathrm{aAB}$ & $2,70 \mathrm{aA}$ & & $2,36 \mathrm{bB}$ & & & 2,79 & & $3 \mathrm{aB}$ & $2,63 \mathrm{aAB}$ & $2,60 \mathrm{aA}$ \\
\hline Agos & $8 \mathrm{aB}$ & $2,36 \mathrm{bA}$ & $2,47 \mathrm{abA}$ & $3 \mathrm{aA}$ & & & $0 \mathrm{aC}$ & $2,16 \mathrm{aAB}$ & & $1,80 \mathrm{bC}$ & $1,87 \mathrm{abB}$ & $2,12 \mathrm{aA}$ \\
\hline Setembro & $2,10 \mathrm{aB}$ & $2,12 \mathrm{aB}$ & $2,07 \mathrm{aB}$ & $2,68 \mathrm{aA}$ & $2,57 \mathrm{aA}$ & $2,59 \mathrm{aA}$ & $2,46 \mathrm{aAB}$ & $2,26 \mathrm{aAB}$ & $2,32 \mathrm{aA}$ & $2,77 \mathrm{aA}$ & $2,41 \mathrm{bAB}$ & $2,36 \mathrm{bAB}$ \\
\hline
\end{tabular}

Coeficiente de variação da análise de variância $=9,2 \%$.

Em um mesmo tratamento, letras minúsculas distintas indicam médias diferentes $(\mathrm{P}<0,05)$ entre dias de ocupação do piquete $(\mathrm{dms}=$ $0,26 \% \mathrm{PV})$

Em um mesmo dia de ocupação do piquete, letras maiúsculas distintas indicam médias diferentes $(\mathrm{P}<0,05)$ entre tratamentos $(\mathrm{dms}=$ $0,41 \% \mathrm{PV})$

Foi observada redução no consumo diário de MS de pastagem nos meses da estação seca em relação ao consumo diário nos meses da estação chuvosa do ano, o que está de acordo com o resultado relatado por Aroeira et al. (1999) e Paciullo et al. (2001). É provável que a decrescente disponibilidade de pasto tenha modulado o consumo de capim-elefante na estação seca, induzindo menor $(\mathrm{P}<0,05)$ consumo em setembro nas pastagens com 30 dias de intervalo, e em agosto-setembro nas pastagens com 36 e 45 dias de intervalo de pastejo.

A regressão do consumo diário de MS de capimelefante $(\% \mathrm{PV})$ nas pastagens sem concentrado (Y) em relação ao mês de avaliação (X) no período de fevereiro a setembro indicou decréscimo $(\mathrm{P}<0,0001)$ de $0,36 \% \mathrm{PV} /$ mês na ingestão de capim-elefante.

Usando separadamente os dados de cada dia de ocupação do piquete nas análises de regressão do consumo de MS da pastagem (Y) em relação ao mês de avaliação $(\mathrm{X})$, foram obtidos decréscimos $(\mathrm{P}<0,0001)$ de 0,$33 ; 0,38$ e $0,39 \% \mathrm{PV} /$ mês no consumo de pastagem, respectivamente, no primeiro, segundo e terceiro dias de ocupação do piquete.

Foi verificado, independentemente do intervalo de pastejo e da suplementação concentrada, incremento no consumo diário de cana mais uréia $(26,8 \%$ de $\mathrm{MS} ; 9,4 \%$ de $\mathrm{PB} ; 57,6 \%$ de FDN; $35,6 \%$ de FDA e 56,8\% de DIVMS) desde junho $(1,0 \% \mathrm{PV})$ até setembro $(1,6 \% \mathrm{PV})$. Consumo superior para cana mais uréia foi observado no terceiro $(1,3 \% \mathrm{PV})$ em relação ao segundo $(1,2 \% \mathrm{PV})$ ou primeiro $(1,2 \% \mathrm{PV})$ dias de ocupação do piquete. Nos tratamentos sem concentrado, a contribuição do capim-elefante no consumo total da dieta na estação seca decresceu de $52 \%$ no primeiro para 47,5 e $43 \%$, respectivamente, no segundo e terceiro dias de ocupação do piquete.

Em agosto, nos tratamentos sem concentrado, foi verificado consumo diário de MS de capimelefante superior $(\mathrm{P}<0,05)$ na pastagem com 30 dias de intervalo de pastejo em relação ao consumo nas demais (Tab. 2). Nesse mês, a diferença no consumo total de MS quanto ao intervalo de pastejo (Tab. 3) foi parcialmente minimizada pelo efeito de substituição do consumo de capim-elefante pelo de cana mais uréia nas pastagens com 36 e 45 dias de intervalo de pastejo.

De junho a setembro, no tratamento com concentrado, de modo geral, não houve diferença $(\mathrm{P}>0,05)$ no consumo diário de MS (capimelefante ou total) entre os três dias de ocupação do piquete. Nos demais tratamentos, padrões diferenciais de consumo de capim-elefante foram observados (Tab. 2). Na pastagem sem concentrado com 30 dias de intervalo de pastejo, de junho a agosto houve maior $(\mathrm{P}<0,05)$ consumo de MS de capim-elefante nos primeiros dias de ocupação do piquete em relação ao terceiro. Em setembro, o consumo entre dias de ocupação do piquete tendeu a se equiparar $(\mathrm{P}>0,05)$, como resposta à mínima disponibilidade de pasto. No tratamento com 36 dias de intervalo de pastejo, esse nivelamento ocorreu ainda em agosto.

$\mathrm{Na}$ estação seca foi verificado menor consumo diário de FDN em comparação ao da estação chuvosa. Isto está relacionado ao decréscimo no consumo diário total, mas também à redução da contribuição dietética do capim-elefante, cujos 
teores de FDN são normalmente superiores aos da cana-de-açúcar. Ademais, a FDN ingerida na estação da seca pode exercer maior efeito de enchimento ruminal, pela baixa degradabilidade e taxa de passagem desta fração na cana-deaçúcar (Aroeira et al., 1995), bem como pela normal redução da capacidade física do rúmen com o avanço no período de gestação das vacas (Ingvartsen, 1994).

\section{CONCLUSÕES}

O consumo suplementar de cana mais $1 \%$ de uréia foi efetivo em minimizar os efeitos negativos da estacionalidade da produção de forragem do capim-elefante. $\mathrm{O}$ valor de $1,2 \% \mathrm{PV} / \mathrm{dia}$, comumente referenciado como padrão de consumo de FDN para vacas em lactação, deve ser considerado com cautela para forrageiras tropicais sob condições de pastejo. Os semelhantes resultados de composição química e de consumo diário de MS de pastagem para os diferentes intervalos de pastejo sugerem a adoção do intervalo de pastejo de 30 dias. Em relação aos demais, esse intervalo de pastejo exige menor número de piquetes, facilitando o manejo e reduzindo os custos de produção.

\section{REFERÊNCIAS BIBLIOGRÁFICAS}

AROEIRA, L.J.M.; LOPES, F.C.F.; DAYRELL, M.S. et al. Digestibilidade, degradabilidade e taxa de passagem da cana-de-açúcar mais uréia e do farelo de algodão em vacas mestiças Holandês x Zebu em lactação. Rev. Soc. Bras. Zootec., v.24, p.1016-1026, 1995.

AROEIRA, L.J.M.; LOPES, F.C.F.; DERESZ, F. et al. Daily intake of lactating crossbred cows grazing elephant grass rotationally. Pesq. Agropec. Bras., v.36, p.911-917, 2001.

AROEIRA, L.J.M.; LOPES, F.C.F.; DERESZ, F. et al. Pasture availability and dry matter intake of lactating crossbred cows grazing elephant grass (Pennisetum purpureum, Schum.). Anim. Feed Sci. Technol., v.78, p.313-324, 1999.

ASSIS, A.G. Produção de leite a pasto no Brasil. In: SIMPÓSIO INTERNACIONAL SOBRE PRODUÇÃO ANIMAL EM PASTEJO, Viçosa, 1997. Anais... Viçosa: UFV, 1997. p.381-409.
BALSALOBRE, M.A.A.; CORSI, M.; SANTOS, P.M. Avaliação da digestibilidade in situ de amostras simulando o pastejo em capimelefante (Pennisetum purpureum Schum.). In: REUNIÃO ANUAL DA SOCIEDADE BRASILEIRA DE ZOOTECNIA, 33., Fortaleza, 1996. Anais... Fortaleza: SBZ, 1996. p.274-276.

BENEDETTI, E. Atributos de três gramineas tropicais, parâmetros ruminais e produção de leite em vacas mestiças mantidas a pasto. 1994. 173f. Tese (Doutorado) - Escola de Veterinária, Universidade Federal de Minas Gerais, Belo Horizonte.

CÓSER, A.C.; MARTINS, C.E.; DERESZ, F. $A$ pesquisa em produção de leite a pasto na Embrapa Gado de Leite - 1980 a 1999. Juiz de Fora: Embrapa Gado de Leite, 2000. 32p. (Circular Técnica / Embrapa Gado de Leite, 61).

DERESZ, F. Manejo da pastagem de capimelefante para produção de leite e carne. In: SIMPÓSIO SOBRE CAPIM-ELEFANTE, 2., 1994, Juiz de Fora. Anais... Coronel Pacheco: EMBRAPA-CNPGL, 1994. p.116-138.

DERESZ, F. Utilização do capim-elefante sob pastejo rotativo para a produção de leite $e$ carne. Juiz de Fora, MG: Embrapa Gado de Leite, 1999. 29 p. (Circular Técnica / Embrapa Gado de Leite, 54).

ERBESDOBLER, E.D.; FONTES, C.A.A.; QUEIROZ, D.S. et al. Composição química e disponibilidade do capim-elefante (Pennisetum purpureum, Schum.) cv. Napier, na época das chuvas, sob pastejo. In: REUNIÃO ANUAL DA SOCIEDADE BRASILEIRA DE ZOOTECNIA, 37., Viçosa, 2000. Anais... Viçosa: SBZ, 2000. 1 CD.

INGVARTSEN, K.L. Models of voluntary food intake in cattle. Liv. Prod. Sci., v.39, p.19-38, 1994.

KIMURA, F.T.; MILLER, V.L. Chromic oxide measurement. Improved determination of chromic oxide in cow feed and feces. J. Agric. Food Chem., v.5, p.216, 1957.

LOPES, F.C.F.; AROEIRA, L.J.M. Degradabilidade do capim-elefante (Pennisetum purpureum Schum.) e da cana-de-açúcar (Saccharum officinarum, L.) mais uréia no rúmen de vacas mestiças Holandês x Zebu em lactação. Arq. Bras. Med. Vet. Zootec., v.51, p.383-386, 1999. 
LOPES, F.C.F.; AROEIRA, L.J.M.; NASCIMENTO, J.L. Concentração de amônia no rúmen de vacas mestiças Holandês-Zebu em pastagem de capim-elefante (Pennisetum purpureum Schum.) na estação das chuvas. Arq. Bras. Med. Vet. Zootec., v.50, p.341-343, 1998.

MARTINS, C.E.; CÓSER, A.C.; DERESZ, F. Formação e utilização de pastagem de capimelefante em sistemas intensivos de produção de leite. Juiz de Fora: EMBRAPA-CNPGL-ADT, 1998. 35p. (Circular Técnica / Embrapa Gado de Leite, 50).

MERTENS, D.R. Analysis of fiber in feeds and its uses in feed evaluation and ration formulation. In: SIMPÓSIO INTERNACIONAL DE RUMINANTES, 1992, Lavras. Anais... Lavras: Sociedade Brasileira de Zootecnia, 1992. p.1-32.

PACIULLO, D.S.C.; AROEIRA, L.J.M.; DERESZ, F. et al. Disponibilidade de matéria seca e consumo de forragem de vacas em lactação em pastagem de capim-elefante. In: REUNIÃO ANUAL DA SOCIEDADE BRASILEIRA DE ZOOTECNIA, 38., 2001, Piracicaba. Anais... Piracicaba: SBZ, 2001. p.1092-1093.

ROCHA, R. Avaliação do pasto de capimelefante (Pennisetum purpureum, Schumacher) na produção de leite de vacas mestiças Holandês $x$ Zebu, suplementadas com diferentes fontes alimentares, no periodo da seca. 1987. 76f. Tese (Mestrado) - Escola de Veterinária, Universidade Federal de Minas Gerais, Belo Horizonte.

RODRIGUES, A.A. Potencial e limitações de dietas à base de cana-de-açúcar e uréia para recria de novilhas e para vacas em lactação. In: SIMPÓSIO MINEIRO DE NUTRIÇÃO DE GADO DE LEITE, 2., Belo Horizonte, 1999. Anais... Belo Horizonte: UFMG - Escola de Veterinária, 1999. p.65-75.

SILVA, D.J. Análise de alimentos. Viçosa: UFV/ Imprensa Universitária, 1998. 166p.

SOARES, J.P.G.; AROEIRA, L.J.M.; PEREIRA, O.G. et al. Capim-elefante (Pennisetum purpureum Schum.) sob duas doses de nitrogênio: consumo e produção de leite. Rev. Bras. Zootec., v. 28, p. 889-897, 1999.

TILLEY, J.M.A.; TERRY, R.A. A two-stage technique for the in vitro digestion of forage crops. J. Br. Grassl. Soc., v.18, p.104-111, 1963.

TORRES, R.A. Produção e utilização de forrageiras para suplementação no período da seca. Cana-de-açúcar. In: RELATÓRIO TÉCNICO DA EMBRAPA GADO DE LEITE, 1995-1998. Juiz de Fora: Embrapa Gado de Leite, 1999. p.29-40.

USER'S guide: statistics. Version 5. Cary: SAS Institute, 1985. 956p. 